\title{
Study of Arterial Stiffness - Based on Scientific Evidence, What are the Current Tools for the Study of Arterial Stiffness?
}

\author{
Ronaldo Rodrigues
}

Universidade Federal Fluminense, Niterói, RJ - Brazil.

Editorial referring to the article: Carotid Intima and Media Thickness Correlation with Central Blood Pressure Measurements by Tonometric and Oscillometric Methods: A Proof of Concept.

One of the biggest challenges in modern medicine is the early identification of patients with higher cardiovascular risks. The early identification of vascular damage in hypertensive patients is a challenge for cardiologists around the world in their attempt to reduce the risk of cardiovascular complications in patients. ${ }^{1}$

We know how important it is today to measure the thickness of the carotid intima-media complex through ultrasound examination in order to identify a greater or lesser cardiovascular risk. ${ }^{2}$ Arterial stiffness has proven to be a marker of arterial disease, which is why it has become an important parameter for the assessment of cardiovascular risk. ${ }^{3}$ It is also well-known that ventricular ejection generates a pressure wave that travels through the heart at a certain speed, which is known as the pulse wave velocity (PWV). The study of PWV in the carotid and femoral arteries is considered the gold standard in the assessment of arterial stiffness. ${ }^{4}$

The pulse wave generated by ventricular ejection travels through the arterial system and is regulated by peripheral vascular resistance. The study of the reflected speed in a bifurcation site and the moment of the cardiac cycle when this reflected speed occurs is of great importance. In young patients, the arteries have greater elasticity and, therefore, the reflected wave is slow in reaching the heart during diastole, generating an increase in diastolic pressure levels, thus favoring the perfusion of coronary arteries. ${ }^{5}$ Other methods, such as central systolic

\section{Keywords}

Vascular Stiffness; Pulse Wave Analysis; Elasticity: Circulatory System; Blood Pressure; Carotid Intima Media Thickness. blood pressure measurements and augmentation indexes, are applicable methodologies, but these are influenced by drugs, heart rate, and age, making them less reliable. Aging is always associated with arterial stiffening, but it is well-known that hypertensive disease anticipates and accelerates the process of arterial stiffening . ${ }^{6}$

Several cardiovascular risk factors can be associated with increased arterial stiffness, the main ones being: sedentary lifestyle, smoking, dyslipidemia, glucose intolerance, metabolic syndrome, and diabetes. ${ }^{7}$ In Hypertensive heart disease and Diabetes, the arterial wall undergoes changes, changes that can lead to increased arterial stiffness. Elevated levels of adiponectin have also been associated with aortic stiffness in diabetic patients. ${ }^{8,9}$ The identification through complementary methods of increasing arterial stiffness may suggest damage to the target organ, which is why the study of non-invasive arterial stiffness is so important nowadays. ${ }^{10}$

Other study methodologies can be used, such as applanation tonometry, a method that studies the pressure waves obtained in the carotid and femoral arteries, which is an accurate non-invasive tool in obtaining central hemodynamic measurements. The oscillometric method can also be used. This method studies the pressure waveforms in the brachial or radial arteries, is highly accurate, and can be performed in a simpler manner and with a better cost-benefit ratio, when compared to applanation tonometry.

Mailing Address: Ronaldo Rodrigues

Universidade Federal Fluminense

R. Prof. Lara Vilela, s/n. Postal Code: 24210-590, Niterói, RJ - Brazil.

E-mail: azmeg@globo.com 
The article "Carotid Intima and Media Thickness Correlation with Central Blood Pressure Measurements by Tonometric and Oscillometric Methods: A Proof of Concept", notes that early detection of vascular damage in subclinical stages of hypertensive disease may be the key to further optimizing prevention of cardiovascular outcomes. The increase in carotid artery intima-media thickness (CA-IMT) is a morphological index capable

\section{References}

1. Zuo G, Zhang M, Jia X, Zheng L, Li Y, Zhao H, et al. Correlation between brachial-ankle pulse wave velocity, carotid artery intima-media thickness, anklebrachial index, and the severity of coronary lesions. Cell Biochem Biophys. 2014;70(2):1205-11.

2. Skilton MR, Serusclat A, Sethu AH, Brun S, Bernard S, Balkau B, et al. Noninvasive measurement of carotid extra-media thickness: associations with cardiovascular risk factors and intima-media thickness. JACC Cardiovasc Imaging. 2009;2(2):176-82.

3. Gurovich AN, Braith RW. Pulse wave analysis and pulse wave velocity techniques: are they ready for the clinic? Hypertens Res. 2011;34(2):166-9.

4. Townsend RR, Wilkinson IB, Schiffrin EL, Avolio AP, Chirinos JA, Cockcroft JR, et al; American Heart Association Council on Hypertension. Recommendations for improving and standardizing vascular research on arterial stiffness: a scientific statement from the American Heart Association. Hypertension. 2015;66(3):698-722.

5. Nichols W, O'Rourke M, Viachopoulos C. McDonald's blood flow in arteries: theoretical, experimental and clinical principles. 6th ed. New York:CRC Press; 2011.

6. Tsis V, Stabouli S, Karafillis I, Nilsson P. Early vascular aging and the role of central blood pressure. J Hypertens. 2011;29(10):1847-53. of detecting early damage, and today it is a variable used in stratifying cardiovascular risk. The assessment of arterial stiffness obtained through pulse wave velocity (PWV) and CA-IMT are considered, by the main guidelines of arterial hypertension, important markers of cardiovascular risk, especially in the early stages of hypertension and in groups of low and intermediate risk. ${ }^{11}$

7. Safar ME, Levy BI, Struijker-Boudier H. Current perspectives on arterial stiffness and pulse pressure in hypertension and cardiovascular diseases. Circulation. 2003;107(22):2864-9.

8. Brooks BA, Molyneaux LM, Yue DK. Augmentation of central arterial pressure in Type 2 diabetes. Diabet Med. 2001;18(5):374-80.

9. Tsioufis C, Dimitriadis K, Selima M, Thomopoulos C, Mihas C, Skiadas I, et al. Low-grade inflammation and hypoadiponectinaemia have an additive detrimental effect on aortic stiffness in essential hypertensive patients. Eur Heart J. 2007;28(9):1162-9.

10. Vlachopoulos C, Xaplanteris P, Aboyans V, Brodmann M, Cifkova R, Cosentino F, et al. The role of vascular biomarkers for primary and secondary prevention. A position paper from the European Society of Cardiology Working Group on peripheral circulation: Endorsed by the Association for Research into Arterial Structure and Physiology (ARTERY) Society. Atherosclerosis. 2015;241(2):507-32.

11. Barroso WKS, Melo MA, Vitorino PV, Gonçalves C, Berigó JA, Arantes AC et al . Carotid Intima and Media Thickness Correlation with Central Blood Pressure Measurements by Tonometric and Oscillometric Methods: A Proof of Concept. Int. J. Cardiovasc. Sci. 2021; 34(1):22-29. 